\title{
Solvent Exposures and Parkinson Disease Risk in Twins
}

\author{
Samuel M. Goldman, MD, MPH, ${ }^{1}$ Patricia J. Quinlan, MPH, ClH, ${ }^{2}$ G. Webster Ross, MD, ${ }^{3}$ \\ Connie Marras, MD, PhD, ${ }^{4}$ Cheryl Meng, MS, ${ }^{1}$ Grace S. Bhudhikanok, PhD, ${ }^{1}$ \\ Kathleen Comyns, MPH, ${ }^{1}$ Monica Korell, MPH, ${ }^{1}$ Anabel R. Chade, MD, ${ }^{5}$ \\ Meike Kasten, MD, ${ }^{6}$ Benjamin Priestley, MPH, ${ }^{1}$ Kelvin L. Chou, MD, ${ }^{7}$ \\ Hubert H. Fernandez, MD, ${ }^{8}$ Franca Cambi, MD, PhD, ${ }^{9}$ \\ J. William Langston, $\mathrm{MD},{ }^{1}$ and Caroline M. Tanner, MD, $\mathrm{PhD}^{1}$
}

\begin{abstract}
Objective: Several case reports have linked solvent exposure to Parkinson disease (PD), but few studies have assessed associations with specific agents using an analytic epidemiologic design. We tested the hypothesis that exposure to specific solvents is associated with PD risk using a discordant twin pair design.

Methods: Ninety-nine twin pairs discordant for PD ascertained from the National Academy of Sciences/National Research Council World War II Veteran Twins Cohort were interviewed regarding lifetime occupations and hobbies using detailed job task-specific questionnaires. Exposures to 6 specific solvents selected a priori were estimated by expert raters unaware of case status.

Results: Ever exposure to trichloroethylene (TCE) was associated with significantly increased risk of PD (odds ratio [OR], 6.1; 95\% confidence interval [CI] 1.2-33; $p=0.034)$, and exposure to perchloroethylene (PERC) and carbon tetrachloride $\left(\mathrm{CCl}_{4}\right)$ tended toward significance (respectively: OR, 10.5; 95\% Cl, 0.97-113; $p=0.053 ; \mathrm{OR}, 2.3 ; 95 \%$ $\mathrm{Cl}, 0.9-6.1 ; p=0.088$ ). Results were similar for estimates of exposure duration and cumulative lifetime exposure.

Interpretation: Exposure to specific solvents may increase risk of PD. TCE is the most common organic contaminant in groundwater, and PERC and $\mathrm{CCl}_{4}$ are also ubiquitous in the environment. Our findings require replication in other populations with well-characterized exposures, but the potential public health implications are substantial.
\end{abstract}

ANN NEUROL 2012;71:776-784

Solvents are present in a wide range of products, such

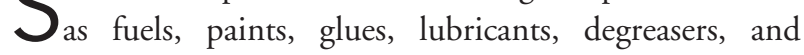
cleaning products. They have long been suspected as potential causative agents in typical Parkinson disease $(\mathrm{PD})$, in part because of anecdotal reports of parkinsonism occurring in individuals with large exposures. ${ }^{1-5}$ Recently, Gash and colleagues reported a cluster of 3 individuals with PD who had extensive exposures to the solvent trichloroethylene (TCE) in a small manufacturing plant. ${ }^{6}$ Several other cases possibly related to TCE have also been reported, ${ }^{7,8}$ but there are no analytic epidemiologic studies investigating a possible association with PD. TCE is the most frequently reported organic contami- nant in groundwater. ${ }^{9,10}$ If solvents such as TCE are associated with PD risk, the public health implications could be substantial.

For these reasons, we conducted a case-control study to determine whether there are associations with specific solvents that have been anecdotally associated with PD, including TCE, tetrachloroethylene (also known as perchloroethylene [PERC]), carbon tetrachloride $\left(\mathrm{CCl}_{4}\right)$, toluene, xylene, and $n$-hexane. We utilized a population of twins discordant for PD with well-characterized exposure to solvents and other environmental factors. Because twins are genetically very similar or identical, and share many demographic and lifestyle factors, discordant twin-pair 
designs are more resistant to confounding factors than typical case-control study designs. ${ }^{11}$

\section{Subjects and Methods}

\section{Case Ascertainment}

Study subjects were members of the National Academy of Sciences/National Research Council World War II Veteran Twins Registry, an all-male twin cohort established in the 1960s using military records. ${ }^{12}$ Detailed methods have been previously published. ${ }^{13}$ Briefly, from 1993 to 1995 , we attempted to contact all 19,842 individual twins believed to be alive and administered a brief telephone interview screening for symptoms of parkinsonism. ${ }^{14}$ Cases from the Twin Registry were also ascertained through searches of medical databases of the Department of Veteran Affairs, the Health Care Financing Administration, and the National Death Index, by referral from an ongoing study of dementia in the registry, ${ }^{15}$ and through a second cohort-wide screen conducted 5 years later. Twins with suspected parkinsonism and their twin brothers received an in-person evaluation by a movement disorders specialist that included a neurological exam and scripted videotaping of the exam. Medical records were also obtained. Diagnosis was determined by consensus of 2 neurologists using all available information, applying standard criteria. ${ }^{16-18}$ We identified 220 individual twins with PD.

The study received institutional review board approval, and all participants provided written informed consent.

\section{Exposure Assessment}

Lifetime exposures were inferred for 6 specific solvents that had been previously linked to PD or parkinsonism in case reports or analytic studies: $n$-hexane, xylene, toluene, $\mathrm{CCl}_{4}, \mathrm{TCE}$, and PERC. We utilized occupational exposure assessment methods previously developed for cancer research. ${ }^{19-22}$ Fifty-two job taskspecific structured questionnaires were adapted from Stewart et $\mathrm{al}^{23}$ or developed de novo to collect highly detailed task-, process-, and material-specific information for a broad range of occupations. These instruments could be administered consistently by interviewers without specialized industrial hygiene training. Initial interviews collected occupational history overviews for all jobs held $>6$ months from age 10 years onward, including detailed information on years of employment, company name and location, products made, job titles, and a description of the tasks performed in each job. Hobby histories were also collected. Historical overviews were reviewed to assign the appropriate job task-specific structured questionnaires for subsequent interviews.

The industrial hygienist and/or occupational medicine physician, unaware of case status, reviewed all available occupational information. Using extensive probability databases ${ }^{24}$ (E.A. Katz, unpublished data; J. Siemiatycki, unpublished data) and multiple reference sources, ${ }^{19,23,25-29}$ solvent exposures were inferred for each job in the context of the subject's detailed description of the job or hobby, industry, tasks, and time period. ${ }^{19,21,27,30,31}$ Ever exposure to a solvent was defined as exposure at least $2 \%$ of work time or 1 hour per week. Exposure intensity was coded for each job or hobby as low, medium, or high, corresponding to 2.5 parts per million (ppm), 25ppm, and $100 \mathrm{ppm}$ respectively. ${ }^{32,33} \mathrm{~A}$ cumulative exposure index (CEI) was calculated for each solvent as the product of exposure intensity, hours exposed per year, and years exposed, summing across all jobs and hobbies. A combined variable for exposure to either TCE or PERC was also considered, because these compounds are thought to share toxic properties. ${ }^{34-36}$

Additional questionnaires collected data on lifetime history of smoking and head injury. Smoking was defined as smoking at least 1 cigarette per day for 6 months or longer. ${ }^{37}$ Head injury was defined as ever having a head injury that resulted in a loss of consciousness or amnesia. ${ }^{38}$ Trained interviewers administered all risk factor questionnaires by telephone. Suitable proxy informants were identified for deceased and $\operatorname{cog}$ nitively impaired subjects scoring $<27$ on the educationadjusted Modified Telephone Interview for Cognitive Status. ${ }^{39}$

\section{Statistical Analysis}

Paired analyses were performed in monozygotic (MZ) and dizygotic (DZ) twins discordant for PD. For all risk variables, observations for both twins were truncated at the PD diagnosis age in the affected twin or the last year for which information was available (the index date), whichever was earlier. Continuous variables were compared using Wilcoxon signed-rank tests. McNemar test with exact $p$ values was used for dichotomous variables. All reported $p$ values are 2-tailed. Exposure duration and CEI were analyzed as tertiles based on their distribution in control twins. For PERC exposure duration, tertiles were based on its distribution in all subjects, because few controls were exposed. Conditional logistic regression to account for matching within twin pairs was used to adjust for potential confounding by smoking and respondent type (subject or proxy), and to calculate odds ratios (ORs) and 95\% confidence intervals (CIs) for each solvent.

Sensitivity analyses considered occupational exposures only (ie, excluding hobby-related exposures), as well as models adjusted for head injury and smoking pack-years, stratified by zygosity, and lagged to exclude solvent exposures within 10 years of the index date. Because matched-pair analyses exclude individuals for whom paired data are incomplete, a sensitivity analysis also measured solvent associations with PD in unpaired models. Analyses were conducted with SPSS version 12.0 (http://spss.com).

\section{Results}

A total of 198 PD-discordant pairs were identified (85 MZ, 110 DZ, 3 unknown zygosity). Occupational histories were completed by 126 (63.6\%) individual twins with PD, 119 (60.1\%) individual twins without PD, and by both twins in 99 pairs (49 MZ, 50 DZ; Table 1). Among these, interviews were completed with proxy informants for $46.5 \%$ of twins with PD and $18.2 \%$ of control twins. Most proxy informants were spouses (58\%), twin brothers $(22 \%)$, or other siblings (13\%). Age at PD diagnosis and age at interview of twins who completed the interview were similar to those of noncompleting twins. 


\begin{tabular}{|c|c|c|c|}
\hline \multicolumn{2}{|l|}{ Characteristic } & \multicolumn{2}{|l|}{ Value } \\
\hline \multicolumn{4}{|l|}{ Age at $\mathrm{PD}$ diagnosis, mean $(\mathrm{SD})$, range } \\
\hline \multicolumn{2}{|c|}{ Individual twins with PD who completed interview, $\mathrm{n}=126$} & \multicolumn{2}{|c|}{$66.2(8.7), 35-84$} \\
\hline \multicolumn{2}{|c|}{ Both members of twin pair completed interview, $\mathrm{n}=99$} & \multicolumn{2}{|c|}{$65.4(8.3), 39-83$} \\
\hline \multicolumn{2}{|c|}{ Individual twins with PD who did not complete interview, $\mathrm{n}=72$} & \multicolumn{2}{|c|}{$68.8(9.5), 25-87$} \\
\hline \multicolumn{4}{|c|}{ PD duration at time of interview, mean (SD), range } \\
\hline \multicolumn{2}{|c|}{ Individual twins with PD who completed interview } & \multicolumn{2}{|c|}{$7.6(6.8), 0-34$} \\
\hline \multicolumn{2}{|c|}{ Both members of twin pair completed interview } & \multicolumn{2}{|c|}{$8.0(6.5), 0-30$} \\
\hline \multicolumn{2}{|c|}{ Individual twins with PD who did not complete interview } & \multicolumn{2}{|c|}{$7.1(7.9), 0-50$} \\
\hline \multicolumn{4}{|l|}{ Zygosity } \\
\hline \multicolumn{2}{|l|}{ Completing pairs, $\mathrm{n}=99$} & \multicolumn{2}{|c|}{$49 \mathrm{MZ} ; 50 \mathrm{DZ}$} \\
\hline \multicolumn{2}{|l|}{ Noncompleting pairs, $\mathrm{n}=99$} & \multicolumn{2}{|c|}{$36 \mathrm{MZ} ; 60 \mathrm{DZ} ; 3$ unknown } \\
\hline $\begin{array}{l}\text { Characteristics in Pairs Completing } \\
\text { Interview, } n=99 \text { pairs }\end{array}$ & $\begin{array}{l}\text { PD-Affected } \\
\text { Twin }\end{array}$ & $\begin{array}{l}\text { PD-Unaffected } \\
\text { Twin }\end{array}$ & $\boldsymbol{P}$ \\
\hline Proxy respondent proportion & $46 \%$ & $18 \%$ & $<0.001$ \\
\hline Ever regular cigarette smoking & $54 \%$ & $62 \%$ & 0.3 \\
\hline Pack-years cigarette smoking, mean (SD) & $16(23)$ & $24(31)$ & 0.024 \\
\hline Ever head injury & $24 \%$ & $9 \%$ & 0.015 \\
\hline
\end{tabular}

Frequencies of ever being exposed to each solvent and the most commonly associated job or hobby types are shown in Table 2. Associations with job categories tended toward significance only for industrial machinery repairer (OR, 3.0; 95\% CI, 0.8-11.2), and industrial worker (OR, 2.3; 95\% CI, 0.9-5.9). Exposure frequencies in twin pairs (ie, either twin was exposed) ranged from $6 \%$ for PERC to $27 \%$ for toluene, and in $48 \%$ of pairs at least 1 twin was exposed to 1 or more of the 6 solvents studied. ORs for ever being exposed were greater than unity for every solvent (Table 3). The adjusted OR was significantly increased for TCE (OR, 6.1; 95\% CI, $1.2-33 ; p=0.034)$ and tended toward significance for PERC (OR, 10.5; 95\% CI, 0.97-113; $p=0.053$ ) and $\mathrm{CCl}_{4}$ (OR, 2.3; 95\% CI, 0.9-6.1, 0.088). Risk was also significantly increased for the combined variable TCE or PERC exposure (OR, 8.9; 95\% CI, 1.7-47; $p=0.01$ ). Risk was modestly, although nonsignificantly, increased for exposure to any of the 6 solvents, or any of 4 solvents excluding PERC and TCE. Risk associated with TCE or PERC exposure was only minimally attenuated when a variable for exposure to any of the other 4 solvents was included in the model (OR, 8.3; 95\% CI, 1.6-44; $p=0.013)$. Mean time from first exposure until index date ranged from 25 years for $n$-hexane to 41 years for xylene (Table 4). Solvent exposure was not significantly associated with PD diagnosis age, but we had limited power to assess this relationship.

Associations with exposure duration and CEI were similar to those for ever exposure, with significantly increased risk for TCE and near significance for PERC (see Table 4). For every solvent, exposure estimates were lower for proxy-provided than for subject-provided occupational histories in both case and control subjects. Although precision was reduced, results were similar when pairs with a proxy respondent were excluded from analyses (TCE: OR, 6.0; 95\% CI, 0.7-50; TCE or PERC: OR, 7.0; 95\% CI, 0.9-57). Results were also similar in models that excluded hobby-related exposures or that included head injury or smoking pack-years, or were stratified by zygosity (data not shown), as well as in unmatched analyses (Table 5).

\section{Discussion}

To the best of our knowledge, this is the first confirmation of a significant association between TCE exposure 


\begin{tabular}{|c|c|c|c|c|}
\hline Solvent & $\begin{array}{l}\text { Case } \\
\text { Exposure } \\
\text { Frequency }\end{array}$ & $\begin{array}{l}\text { Control } \\
\text { Exposure } \\
\text { Frequency }\end{array}$ & $\begin{array}{l}\text { Proportion of } \\
\text { Pairs With Either } \\
\text { Twin Exposed }\end{array}$ & $\begin{array}{l}\text { Most Frequent } \\
\text { Job or Hobby Types With Exposure } \\
\text { (in order of frequency) }\end{array}$ \\
\hline Toluene & $18 \%$ & $16 \%$ & $27 \%$ & $\begin{array}{l}\text { Cabinet maker, artist, mechanic, } \\
\text { electrician, carpenter }\end{array}$ \\
\hline Xylene & $9 \%$ & $5 \%$ & $11 \%$ & $\begin{array}{l}\text { Artist, laboratory technician, } \\
\text { groundskeeper, cabinet maker }\end{array}$ \\
\hline n-Hexane & $7 \%$ & $8 \%$ & $14 \%$ & $\begin{array}{l}\text { Cabinet maker, carpenter, } \\
\text { mechanic, shoemaker }\end{array}$ \\
\hline $\mathrm{CCl}_{4}$ & $16 \%$ & $11 \%$ & $25 \%$ & $\begin{array}{l}\text { Electrician, mechanic, aircraft mechanic, } \\
\text { painter, dry cleaner, industrial worker }\end{array}$ \\
\hline PERC & $5 \%$ & $1 \%$ & $6 \%$ & Electrician, dry cleaner, artist \\
\hline TCE & $10 \%$ & $3 \%$ & $12 \%$ & $\begin{array}{l}\text { Electrician, dry cleaner, industrial } \\
\text { machinery repairer, health worker }\end{array}$ \\
\hline TCE or PERC & $12 \%$ & $3 \%$ & $14 \%$ & $\mathrm{n} / \mathrm{a}$ \\
\hline Any of 6 solvents & $34 \%$ & $29 \%$ & $48 \%$ & $\mathrm{n} / \mathrm{a}$ \\
\hline
\end{tabular}

and PD risk in a population-based study. Two other chlorinated solvents, PERC and $\mathrm{CCl}_{4}$, tended toward significantly increased risk. Results were similar in analyses considering ever/never exposure, exposure duration, or lifetime cumulative exposure. Our findings are consistent with prior case reports ${ }^{6-8}$ and a rodent model of TCE- induced parkinsonism that recapitulates key pathological and neurochemical features of PD. ${ }^{40}$ In this model, TCE caused selective dose-dependent loss of dopaminergic neurons in the substantia nigra pars compacta (SNpc), and selective accumulation of $\alpha$-synuclein protein in the dorsal motor nucleus of the vagus nerve and $\mathrm{SNpc}$, a

\section{TABLE 3: Solvent Exposure Frequencies and Adjusted Pairwise Odds Ratios in PD-Discordant Twins, $n=99$ Pairs $^{\mathrm{a}}$}

\begin{tabular}{|c|c|c|c|c|c|c|}
\hline Solvent & $\begin{array}{l}\text { Case }^{-} \text {I } \\
\text { Control }^{-}\end{array}$ & $\begin{array}{l}\text { Case }^{+} \text {I } \\
\text { Control }^{-}\end{array}$ & $\begin{array}{l}\text { Case }^{-} / \\
\text {Control }^{+}\end{array}$ & $\begin{array}{l}\text { Case }^{+} / \\
\text {Control }^{+}\end{array}$ & $\begin{array}{l}\text { Ever/Never } \\
\text { Exposed, } \\
\text { OR }(95 \% \text { CI })\end{array}$ & $p$ \\
\hline Toluene & 72 & 11 & 9 & 7 & $1.3(0.5-3.3)$ & $>0.2$ \\
\hline Xylene & 88 & 6 & 2 & 3 & $2.2(0.4-12)$ & $>0.2$ \\
\hline n-Hexane & 85 & 6 & 7 & 1 & $1.3(0.4-4.1)$ & $>0.2$ \\
\hline $\mathrm{CCl}_{4}$ & 74 & 14 & 9 & 2 & $2.3(0.9-6.1)$ & 0.088 \\
\hline PERC & 93 & 5 & 1 & 0 & $10.5(0.97-113)$ & 0.053 \\
\hline TCE & 87 & 9 & 2 & 1 & $6.1(1.2-33)$ & 0.034 \\
\hline TCE or PERC & 85 & 11 & 2 & 1 & $8.9(1.7-47)$ & 0.010 \\
\hline Any of 6 solvents & 51 & 19 & 14 & 15 & $1.7(0.8-3.7)$ & 0.16 \\
\hline $\begin{array}{l}\text { Any of } 4 \text { excluding } \\
\text { TCE and PERC }\end{array}$ & 53 & 18 & 15 & 13 & $1.5(0.7-3.1)$ & $>0.2$ \\
\hline
\end{tabular}




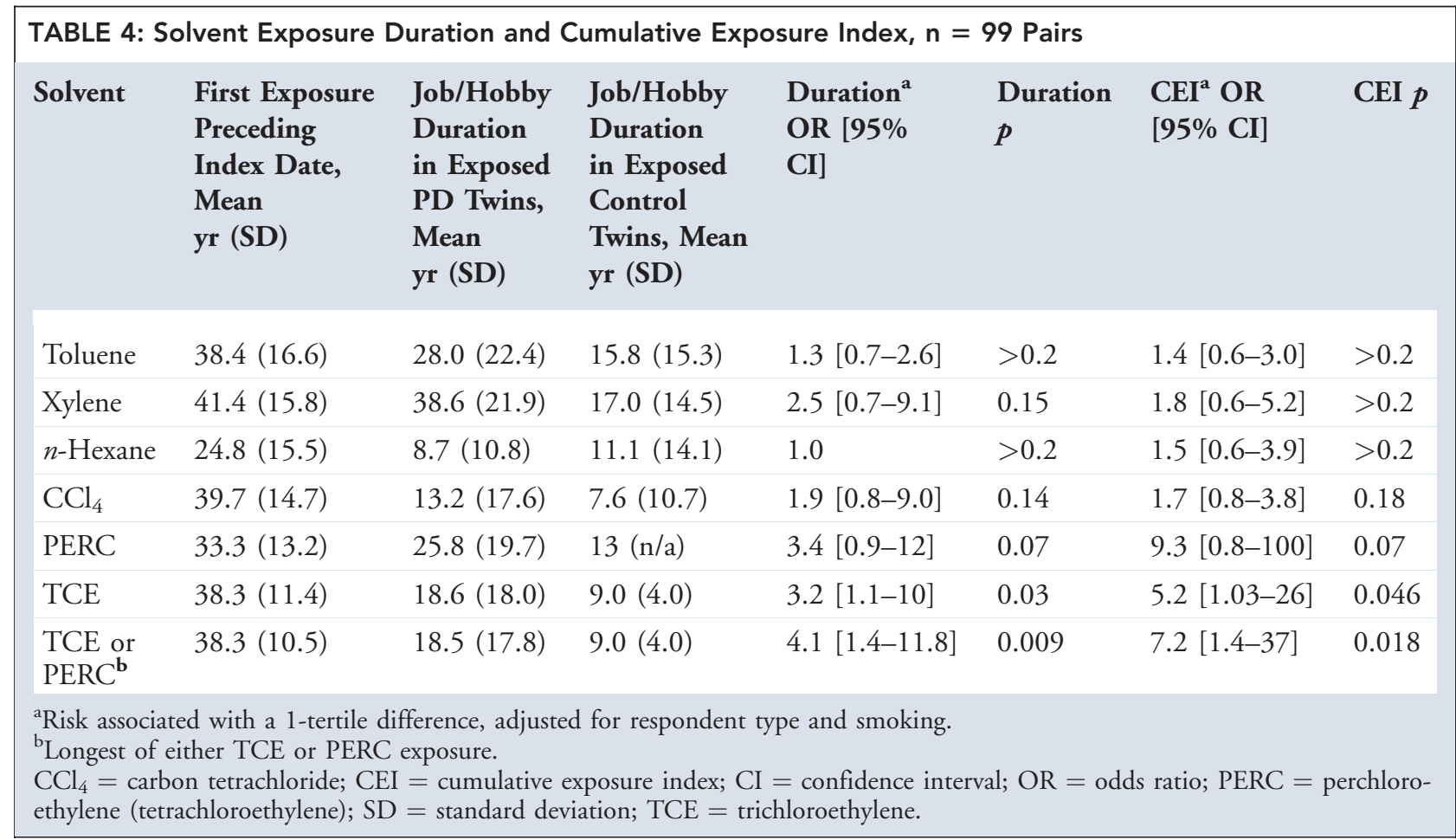

pattern consistent with human pathological staging of PD. ${ }^{41}$ TCE also reduced mitochondrial complex 1 activity, similar to the neurotoxin 1-methyl-4-phenylpyridinium $\left(\mathrm{MPP}^{+}\right)$, the insecticide rotenone, and the mitochondrial deficiency seen in typical PD. ${ }^{42,43}$ Like TCE, PERC ${ }^{44,45}$ and $\mathrm{CCl}_{4}{ }^{46-48}$ have also been shown to increase markers of oxidative and nitrative stress, activate microglia, and disrupt mitochondrial function. ${ }^{49-53}$ Because of their lipophilic nature, each of these com- pounds readily distributes in body tissues and particularly the brain. ${ }^{10,54,55}$

TCE, PERC, and $\mathrm{CCl}_{4}$ have been used extensively worldwide for decades. ${ }^{10,56,57}$ TCE has been used as a dry cleaning and degreasing agent, and as an additive in many common household products, including typewriter correction fluid, adhesives, paints, and carpet cleaners and spot removers. In 1977, the US Food and Drug Administration banned its use as a general anesthetic,

\begin{tabular}{|c|c|c|c|c|c|c|c|c|}
\hline Solvent & $\begin{array}{l}\text { Case } \% \\
\text { Exposed, } \\
n=126\end{array}$ & $\begin{array}{l}\text { Control \% } \\
\text { Exposed, } \\
\mathbf{n}=119\end{array}$ & $\begin{array}{l}\text { Ever/Never } \\
\text { OR }(95 \% \\
\mathrm{CI})^{\mathrm{a}}\end{array}$ & $\begin{array}{l}\text { Ever/ } \\
\text { Never } \\
p\end{array}$ & $\begin{array}{l}\text { Duration }^{\mathbf{a}}, \mathbf{b} \\
\text { OR }(95 \% \\
\text { CI) }\end{array}$ & $\begin{array}{l}\text { Duration } \\
p\end{array}$ & $\begin{array}{l}\mathrm{CEI}^{\mathrm{a}}, \mathbf{b} \text { OR } \\
(95 \% \mathrm{CI})\end{array}$ & CEI $p$ \\
\hline Xylene & $7.9 \%$ & $5.9 \%$ & $1.5(0.5-4.2)$ & $>0.2$ & $1.5(0.8-3.0)$ & 0.25 & $1.4(0.5-3.8)$ & $>0.2$ \\
\hline Toluene & $15.9 \%$ & $16.0 \%$ & $1.2(0.6-2.4)$ & $>0.2$ & $1.4(0.8-2.4)$ & $>0.2$ & $1.0(0.4-2.2)$ & $>0.2$ \\
\hline n-Hexane & $5.6 \%$ & $9.2 \%$ & $0.8(0.3-2.2)$ & $>0.2$ & $0.7(0.3-1.9)$ & $>0.2$ & $0.4(0.14-1.3)$ & 0.13 \\
\hline $\mathrm{CCl}_{4}$ & $16.7 \%$ & $10.9 \%$ & $2.2(1.0-4.9)$ & 0.043 & $1.8(0.95-3.5)$ & 0.07 & $2.2(0.85-5.8)$ & 0.11 \\
\hline PERC & $4.0 \%$ & $0.8 \%$ & $6.5(0.7-58)$ & 0.096 & $4.9(0.7-35)$ & 0.12 & $5.4(0.7-44)$ & 0.11 \\
\hline TCE & $7.9 \%$ & $2.5 \%$ & $3.3(0.97-11)$ & 0.056 & $3.1(1.0-9.7)$ & 0.05 & $3.1(1.03-9.1)$ & 0.043 \\
\hline $\begin{array}{l}\text { TCE or } \\
\text { PERC }\end{array}$ & $9.5 \%$ & $2.5 \%$ & $3.8(1.2-13)$ & 0.027 & $3.6(1.2-10.3)$ & 0.018 & $3.7(1.2-11)$ & 0.02 \\
\hline
\end{tabular}




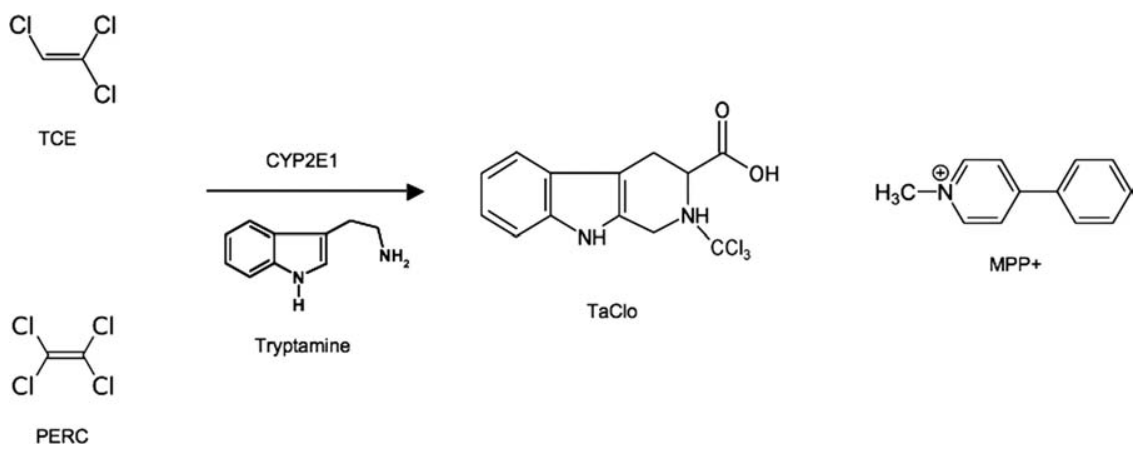

FIGURE: TaClo (1-trichloromethyl-1,2,3,4-tetrahydro- $\beta$-carboline) hypothesis. ${ }^{34}$ CYP2E1 = cytochrome P-450 2E1; MPP+ = 1methyl-4-phenylpyridinium; PERC = perchloroethylene (tetrachloroethylene); TCE = trichloroethylene.

skin disinfectant, grain fumigant, and coffee decaffeinating agent. ${ }^{10}$ Today, it is primarily used as a degreasing agent in metal parts fabrication. Millions of pounds of TCE are still released annually into the environment in the United States. It is detected in air, soil, food, and human breast milk, and is the most frequently reported organic contaminant in groundwater, found in up to $30 \%$ of US drinking water supplies. ${ }^{10,54,55}$

Uses of PERC are similar to those of TCE. ${ }^{56}$ PERC has been the leading dry cleaning solvent since the $1950 s^{58}$ It is also used in textiles manufacturing and as a degreasing agent, and is found in many common household products. PERC persists in air and groundwater for several months or longer and is ubiquitous in human tissues. $\mathrm{CCl}_{4}$ was the first chlorinated solvent used in dry cleaning, predominating from 1930 until the early 1950s. The major use of $\mathrm{CCl}_{4}$ has historically been for the production of chlorofluorocarbons for use as refrigerants. $\mathrm{CCl}_{4}$ has also been used as an anesthetic and anti-helminth, and in common household products. Until recently, it was used as a fumigant to kill insects in grain. Because of its toxicity, consumer and fumigant uses were phased out by 2000, but industrial uses remain. $\mathrm{CCl}_{4}$ is a stable chemical that is degraded very slowly, so it has gradually accumulated in the environment, mainly the atmosphere. ${ }^{57}$

TCE and PERC are primarily metabolized by CYP2E1 and glutathione transferase. ${ }^{35,45}$ A proposed proximate toxic species is 1-trichloromethyl-1,2,3,4-tetrahydro$\beta$-carboline, a potent mitochondrial complex 1 inhibitor, dopaminergic toxin, and structural analogue of $\mathrm{MPP}^{+}$that forms in the presence of tryptamine after CYP2E1-mediated oxidation (Fig). ${ }^{34,59,60}$ Consistent with this hypothesis, pooled exposure to either TCE or PERC was associated with markedly increased PD risk in our study.

Although odds ratios were greater than unity for the other solvents studied, their magnitude of association with PD was modest, and none approached significance. Similarly, risk associated with exposure to any solvent or with job categories was modest and nonsignificant. This is consistent with the modest associations reported by 2 prior mortality studies, ${ }^{61,62}$ and the lack of association reported by others, ${ }^{63-65}$ when broadly defined occupational solvent exposure categories were used.

The term solvent encompasses a wide range of compounds, whose only common characteristics are their ability to dissolve other substances. Although most solvents are oxidative stressors, ${ }^{66-68}$ there is little reason to assume these disparate molecular compounds share a common neuronal toxicity. ${ }^{69}$ Because most prior studies of occupational solvents and PD explored exposures in a nonspecific manner, relationships with any particular etiologic agent may have been obscured.

This study has several strengths. Because twins share both genes and environment, the discordant twin pair design is more resistant to confounding by unrecognized genetic and environmental factors than standard case-control designs, reducing the likelihood of spurious results. ${ }^{11}$ We used validated exposure assessment methods to minimize reporting bias. The traditional method to obtain retrospective exposure information is to directly query subjects about use of specific compounds, but this method is prone to recall bias-the predilection of case subjects to report exposures due to heightened awareness or concern-and workers are often unaware of the specific chemicals they are exposed to. ${ }^{70-72}$ Another strategy requires highly trained interviewers who can probe for specific exposures, an approach that can introduce bias and is impractical when many industries and jobs are being studied. To address these problems, we developed and systematically administered detailed, structured, task-based occupational questionnaires. Participants were unaware of study hypotheses, and exposure inference was based on job tasks rather than self-reported exposures, helping to reduce recall bias. In addition, exposure classification bias was minimized because expert raters were unaware of subject case status.

The major limitations of the study are its small sample size, which yielded imprecise risk estimates, and exposure inferences based on retrospective recall—a virtually 
unavoidable limitation for a disease such as PD, in which relevant exposures may occur decades before clinical disease is apparent. Although our methods helped reduce recall bias, exposure estimation without direct measurement is imprecise. However, because raters were unaware of case status, exposure misclassification would be toward the null, reducing the likelihood of finding a significant association. Another weakness is reliance on proxy informants for a large proportion of subjects, with a much greater proportion among case subjects. However, assigning exposures based on job tasks rather than relying exclusively on self-reported chemical exposures should help mitigate lack of knowledge on the part of the proxy. Furthermore, because exposure estimates were lower for proxy-provided histories than for subject-provided histories, bias would be expected to reduce rather than inflate apparent disease associations. Finally, we adjusted for respondent type in all logistic models, and results were similar when proxy respondents were excluded from analyses. Another limitation is the difficulty isolating specific effects of single agents, because many work settings involve exposure to multiple agents. Nonetheless, our results were not uniform across solvents, suggesting specific effects of individual agents, and associations with TCE or PERC were only minimally attenuated when a variable for exposure to other solvents was included in logistic models.

Although the present work focused on occupational exposures, solvents are ubiquitous in the environment, and this is particularly true for those implicated in this study-TCE, PERC, and $\mathrm{CCl}_{4}$. Our findings require replication in other populations with well-characterized exposures, but the potential public health implications are considerable. One remarkable observation made in all the reports linking TCE exposure with $\mathrm{PD}$ is the very long time lag (10-40 years) between exposure and clinical disease. These observations suggest that exposure may trigger a degenerative cascade dependent on the passage of time, providing a critical window of opportunity to arrest the disease process before clinical symptoms are manifested.

\section{Acknowledgment}

This research was supported by National Institute of Neurological Disorders and Stroke grants RO1-NS40467 (C.M.T.) and U10-NS31321 (C.M.T.), the Michael J. Fox Foundation, Parkinson's Unity Walk, the Valley Foundation, and James and Sharron Clark.

We thank the members of the National Academy of Sciences/National Research Council World War II Veteran Twins Registry.

\section{Potential Conflicts of Interest}

P.J.Q.: grants, National Institute of Environmental Health Sciences. G.W.R.: grants, Parkinson's Institute. K.C.: employment, Parkinson's Institute and Clinical Center. M.Ka.: grants, German Research Foundation; travel expenses, Movement Disorders Society, Melvin Yahr Foundation. K.L.C.: consultancy, Medtronic, Merz Pharmaceuticals; grants/grants pending, Teva Neuroscience, Huntington Study Group, NIH, Michael J. Fox Foundation; speaking fees, Allergan, GlaxoSmithKline, Medtronic, Teva Neuroscience, University of South Florida CME, Cleveland Clinic CME; royalties, UpToDate. H.H.F.: grants, Abbott, EMD Serono, Ipsen, Merz, Novartis, Teva; consulting, Ipsen, US World Meds, Teva, Merz; royalties, Demos, Manson Publishing, Springer. J.W.L.: employment, Parkinson's Institute and Clinical Center. C.M.T.: board membership, Michael J. Fox Foundation Scientific Advisory Board, National Spasmodic Dystonia Association Scientific Advisory Board; consultancy, Impax Pharmaceuticals, Lundbeck Pharmaceuticals, Pacific Health Research Institute (consultant on NIH and Department of Defensefunded research), Stanford University (consultant on Muscular Dystrophy Association-funded research), SunHealth Research Institute (consultant on MJFF-funded research), NeuroPace, Adamas Pharmaceuticals; employment, Parkinson's Institute and Clinical Center, NIH (NANDS-special government employee); grants/grants pending, Michael J. Fox Foundation, Brin Foundation, Parkinson's Institute and Clinical Center, Parkinson's Disease Foundation, USAMRAA (TATRC managed NETRP Program), National Institute of Neurological Disorders and Stroke, Agency for Healthcare and Research Quality, James and Sharron Clark.

\section{References}

1. Guggenheim MA, Couch JR, Weinberg W. Motor dysfunction as a permanent complication of methanol ingestion. Presentation of a case with a beneficial response to levodopa treatment. Arch Neurol 1971;24:550-554

2. Pezzoli G, Barbieri S, Ferrante $C$, et al. Parkinsonism due to n-hexane exposure. Lancet 1989;2:874.

3. McCrank E, Rabheru K. Four cases of progressive supranuclear palsy in patients exposed to organic solvents. Can J Psychiatry 1989;34:934-936.

4. Tetrud JW, Langston JW, Irwin I, Snow B. Parkinsonism caused by petroleum waste ingestion. Neurology 1994;44:1051-1054.

5. Uitti RJ, Snow BJ, Shinotoh H, et al. Parkinsonism induced by solvent abuse. Ann Neurol 1994;35:616-619.

6. Gash DM, Rutland K, Hudson NL, et al. Trichloroethylene: parkinsonism and complex 1 mitochondrial neurotoxicity. Ann Neurol 2008;63:184-192.

7. Guehl D, Bezard E, Dovero S, et al. Trichloroethylene and parkinsonism: a human and experimental observation. Eur J Neurol 1999;6:609-611. 
8. Kochen W, Kohlmuller D, De Biasi P, Ramsay R. The endogeneous formation of highly chlorinated tetrahydro-beta-carbolines as a possible causative mechanism in idiopathic Parkinson's disease. Adv Exp Med Biol 2003;527:253-263.

9. International Agency for Research on Cancer. Monographs on the evaluation of carcinogenic risks to humans. Vol 63 Lyon, France: World Health Organization, 1997

10. Agency for Toxic Substances and Disease Registry. Toxicological profile for trichloroethylene. Atlanta, GA: United States Department of Health and Human Services, 1997.

11. Hubinette A, Cnattingius S, Ekbom A, et al. Birthweight, early environment, and genetics: a study of twins discordant for acute myocardial infarction. Lancet 2001;357:1997-2001.

12. Jablon S, Neel JV, Gershowitz H, Atkinson GF. The NAS-NRC twin panel: methods of construction of the panel, zygosity diagnosis, and proposed use. Am J Hum Genet 1967;19:133-161.

13. Tanner CM, Ottman R, Goldman SM, et al. Parkinson disease in twins: an etiologic study. JAMA 1999;281:341-346.

14. Tanner C, Gilley D, Goetz C. A brief screening questionnaire for parkinsonism. Ann Neurol 1990;28:267-268.

15. Breitner JC, Welsh KA, Gau BA, et al. Alzheimer's disease in the National Academy of Sciences-National Research Council Registry of Aging Twin Veterans. III. Detection of cases, longitudinal results, and observations on twin concordance. Arch Neurol 1995; 52:763-771.

16. Langston JW, Widner H, Goetz CG, et al. Core assessment program for intracerebral transplantations (CAPIT). Mov Disord 1992; 7:2-13.

17. Hughes AJ, Daniel SE, Kilford L, Lees AJ. Accuracy of clinical diagnosis of idiopathic Parkinson's disease: a clinico-pathological study of 100 cases. J Neurol Neurosurg Psychiatry 1992;55:181-184.

18. Gelb DJ, Oliver E, Gilman S. Diagnostic criteria for Parkinson disease. Arch Neurol 1999;56:33-39.

19. Stewart PA, Lees PS, Francis M. Quantification of historical exposures in occupational cohort studies. Scand J Work Environ Health $1996 ; 22: 405-414$

20. Siemiatycki J, Dewar R, Lakhani R, et al. Cancer risks associated with 10 inorganic dusts: results from a case-control study in Montreal. Am J Ind Med 1989;16:547-567.

21. Stewart $P$, Rice $C$, Beatty $P$, et al. A qualitative evaluation of questions and responses from five occupational questionnaires developed to assess exposures. Appl Occup Environ Hyg 2002;17:444-453.

22. Siemiatycki J, Gerin M, Dewar R, et al. Silica and cancer associations from a multicancer occupational exposure case-referent study. IARC Sci Publ 1990;(97):29-42.

23. Stewart PA, Stewart WF, Heineman EF, et al. A novel approach to data collection in a case-control study of cancer and occupational exposures. Int J Epidemiol 1996;25:744-752.

24. Katz EA, Shaw GM, Schaffer DM. Exposure assessment in epidemiologic studies of birth defects by industrial hygiene review of maternal interviews. Am J Ind Med 1994;26:1-11.

25. Burgess W. Recognition of health hazards in industry. 2nd ed. New York, NY: John Wiley \& Sons, 1995.

26. Plog B, Quinlan PJ, eds.. Fundamentals of industrial hygiene. 5th ed. Itasca, IL: National Safety Council, 2002.

27. Stewart WF, Stewart PA. Occupational case-control studies: I. Collecting information on work histories and work-related exposures. Am J Ind Med 1994;26:297-312.

28. Harris RL, ed. Patty's industrial hygiene. 5th ed. New York, NY: John Wiley \& Sons, 2000.

29. Stellman JM, ed. ILO encyclopedia of occupational health and safety. 4th ed. Geneva, Switzerland: International Labor Organization (ILO), 1998.
30. Siemiatycki J, Fritschi L, Nadon L, Gerin M. Reliability of an expert rating procedure for retrospective assessment of occupational exposures in community-based case-control studies. Am J Ind Med 1997;31:280-286.

31. Fritschi L, Nadon L, Benke G, et al. Validation of expert assess ment of occupational exposures. Am J Ind Med 2003;43:519-522.

32. Moore LE, Boffetta P, Karami S, et al. Occupational trichloroethylene exposure and renal carcinoma risk: evidence of genetic susceptibility by reductive metabolism gene variants. Cancer Res 2010;70:6527-6536.

33. Gold LS, Stewart PA, Milliken K, et al. The relationship between multiple myeloma and occupational exposure to six chlorinated solvents. Occup Environ Med 2011;68:391-399.

34. Bringmann G, God R, Feineis D, et al. The TaClo concept: 1-trichloromethyl-1,2,3,4-tetrahydro-beta-carboline ( $\mathrm{TaClo})$, a new toxin for dopaminergic neurons. J Neural Transm Suppl 1995;46:235-244.

35. Lash LH, Fisher JW, Lipscomb JC, Parker JC. Metabolism of trichloroethylene. Environ Health Perspect 2000;108(suppl 2):177-200

36. Lash LH, Parker JC. Hepatic and renal toxicities associated with perchloroethylene. Pharmacol Rev 2001;53:177-208.

37. Tanner CM, Goldman SM, Aston DA, et al. Smoking and Parkinson's disease in twins. Neurology 2002;58:581-588.

38. Goldman SM, Tanner CM, Oakes D, Bhudhikanok GS, Gupta A, Langston JW. Head injury and Parkinson's disease risk in twins. Ann Neurol 2006;60:65-72.

39. Gallo JJ, Breitner JC. Alzheimer's disease in the NAS-NRC Registry of aging twin veterans: IV. Performance characteristics of a two-stage telephone screening procedure for Alzheimer's dementia. Psychol Med 1995;25:1211-1219.

40. Liu M, Choi DY, Hunter RL, et al. Trichloroethylene induces dopaminergic neurodegeneration in Fisher 344 rats. J Neurochem 2010:112:773-783.

41. Braak H, Del Tredici K, Rub U, et al. Staging of brain pathology related to sporadic Parkinson's disease. Neurobiol Aging 2003;24 197-211

42. Di Monte DA. Mitochondrial DNA and Parkinson's disease. Neurology 1991;41(5 suppl 2):38-42; discussion 42-43.

43. Sherer TB, Richardson JR, Testa CM, et al. Mechanism of toxicity of pesticides acting at complex I: relevance to environmental etiologies of Parkinson's disease. J Neurochem 2007;100:1469-1479.

44. Miyazaki Y, Takano T. Impairment of mitochondrial electron transport by tetrachloroethylene. Toxicol Lett 1983;18:163-166.

45. Lash LH, Qian W, Putt DA, et al. Renal toxicity of perchloroethylene and S-(1,2,2-trichlorovinyl)glutathione in rats and mice: sexand species-dependent differences. Toxicol Appl Pharmacol 2002 179:163-171.

46. Boer LA, Panatto JP, Fagundes DA, et al. Inhibition of mitochondrial respiratory chain in the brain of rats after hepatic failure induced by carbon tetrachloride is reversed by antioxidants. Brain Res Bull 2009;80:75-78.

47. Weber LW, Boll M, Stampfl A. Hepatotoxicity and mechanism of action of haloalkanes: carbon tetrachloride as a toxicological model. Crit Rev Toxicol 2003;33:105-136.

48. Manibusan MK, Odin M, Eastmond DA. Postulated carbon tetrachloride mode of action: a review. J Environ Sci Health C Environ Carcinog Ecotoxicol Rev 2007;25:185-209.

49. Ou J, Ou Z, McCarver DG, et al. Trichloroethylene decreases heat shock protein 90 interactions with endothelial nitric oxide synthase: implications for endothelial cell proliferation. Toxicol Sci 2003;73:90-97.

50. Lam HR, Ostergaard G, Guo SX, et al. Three weeks' exposure of rats to dearomatized white spirit modifies indices of oxidative stress in brain, kidney, and liver. Biochem Pharmacol 1994;47: 651-657. 
51. Lopachin RM, Gavin T, Barber DS. Type-2 alkenes mediate synaptotoxicity in neurodegenerative diseases. Neurotoxicology 2008; 29:871-882.

52. Kim MS, Park HR, Park M, et al. Neurotoxic effect of 2,5-hexanedione on neural progenitor cells and hippocampal neurogenesis. Toxicology 2009;260:97-103.

53. Al-Hajri Z, Del Bigio MR. Brain damage in a large cohort of solvent abusers. Acta Neuropathol 2010;119:435-445.

54. Wu C, Schaum J. Exposure assessment of trichloroethylene. Environ Health Perspect 2000;108(suppl 2):359-363.

55. United States Environmental Protection Agency. Toxic release inventory program. Available at: http://www.epa.gov/tri/index.htm. Accessed November 5, 2010.

56. Agency for Toxic Substances and Disease Registry. Toxicological profile for tetrachloroethylene. Atlanta, GA: United States Department of Health and Human Services, 1997.

57. Agency for Toxic Substances and Disease Registry. Toxicological profile for carbon tetrachloride. Atlanta, GA: United States Department of Health and Human Services, 2005.

58. Linn B. Chemicals used in dry cleaning operations. 2009. Available at: http://www.drycleancoalition.org/chemicals/ChemicalsUsedln Drycleaning Operations.pdf

59. Riederer P, Foley $P$, Bringmann $G$, et al. Biochemical and pharmacological characterization of 1-trichloromethyl-1,2,3,4-tetrahydrobeta-carboline: a biologically relevant neurotoxin? Eur J Pharmacol 2002;442:1-16.

60. Heim C, Sontag KH. The halogenated tetrahydro-beta-carboline "TaClo": a progressively-acting neurotoxin. J Neural Transm Suppl 1997;50:107-111.

61. Park RM, Schulte PA, Bowman JD, et al. Potential occupational risks for neurodegenerative diseases. Am J Ind Med 2005;48:63-77.

62. McDonnell L, Maginnis C, Lewis S, et al. Occupational exposure to solvents and metals and Parkinson's disease. Neurology 2003; 61:716-717.
63. Tanner CM, Ross GW, Jewell SA, et al. Occupation and risk of parkinsonism: a multicenter case-control study. Arch Neurol 2009; 66:1106-1113.

64. Dick FD, De Palma G, Ahmadi A, et al. Environmental risk factors for Parkinson's disease and parkinsonism: the Geoparkinson study. Occup Environ Med 2007;64:666-672.

65. Firestone JA, Lundin JI, Powers KM, et al. Occupational factors and risk of Parkinson's disease: a population-based case-control study. Am J Ind Med 2010;53:217-223.

66. Lam HR, Ostergaard G, Ladefoged O. Three weeks' and six months' exposure to aromatic white spirit affect synaptosomal neurochemistry in rats. Toxicol Lett 1995;80:39-48.

67. Mattia CJ, Ali SF, Bondy SC. Toluene-induced oxidative stress in several brain regions and other organs. Mol Chem Neuropathol 1993;18:313-328.

68. Baydas G, Ozveren F, Tuzcu M, Yasar A. Effects of thinner exposure on the expression pattern of neural cell adhesion molecules, level of lipid peroxidation in the brain and cognitive function in rats. Eur J Pharmacol 2005;512:181-187.

69. Mutti A, Franchini I. Toxicity of metabolites to dopaminergic systems and the behavioural effects of organic solvents. $\mathrm{Br} \mathrm{J}$ Ind Med 1987;44:721-723.

70. Hepworth SJ, Bolton A, Parslow RC, et al. Assigning exposure to pesticides and solvents from self-reports collected by a computer assisted personal interview and expert assessment of job codes: the UK Adult Brain Tumour Study. Occup Environ Med 2006;63: 267-272.

71. Blair A, Zahm SH. Methodologic issues in exposure assessment for case-control studies of cancer and herbicides. Am J Ind Med $1990 ; 18: 285-293$.

72. McGuire V, Nelson LM, Koepsell TD, et al. Assessment of occupational exposures in community-based case-control studies. Annu Rev Public Health 1998;19:35-53. 